\title{
Growth patterns and the use of growth hormone in the mucopolysaccharidoses
}

\author{
L.E. Polgreen* and B.S. Miller \\ University of Minnesota, Department of Pediatrics, Division of Endocrinology, Minneapolis, MN, USA
}

Accepted for publication 21 December 2009

\begin{abstract}
Short stature is characteristic of patients with mucopolysaccharidosis (MPS) diseases. For children with skeletal dysplasias, such as MPS, it is important to know the natural history of growth. An understanding of the natural growth pattern in each MPS disease provides a measurement to which treatments can be compared, as well as data which can help families and providers make individualized decisions about growth promoting treatments. Multiple advancements have been made in the treatment of MPS with both hematopoietic cell transplantation (HCT) and enzyme replacement therapy (ERT). The long term benefit of these treatments on growth is unknown. This article will review the published data on growth in children with MPS, and describe preliminary data on the use of human growth hormone (hGH) in children with MPS.
\end{abstract}

Keywords: Growth, growth hormone, mucopolysaccharidoses, MPS, endocrine disease

\section{Introduction}

The mucopolysaccharidoses (MPS) are a group of diseases characterized by various deficiencies in enzymes required for degradation of complex carbohydrates. The enzymatic deficiencies result in the lysosomal accumulation of dermatan sulfate (DS), heparan sulfate (HS), and/or keratan sulfate (KS) in various tissues resulting in multi-system complications [65,98]. The multiple advancements that have recently been made in the treatment of MPS, in both hematopoietic cell transplantation (HCT) and enzyme replacement therapy (ERT), have significantly improved the duration and quality of life for these children. The longterm benefit of these treatments, however, is largely unknown. It seems that liver, spleen, respiratory, and cardiovascular complications of these diseases are significantly diminished [15-17,23,36,38,39,50,60, $87,89,94]$, but that the musculoskeletal, growth, and

* Address for correspondence: Lynda Polgreen, M.D., Assistant Professor, University of Minnesota, Pediatric Endocrinology, Minneapolis, MN, USA. Tel.: +1 (612) 624 4459; E-mail: polgr001@ umn.edu. endocrine abnormalities are not entirely alleviated by these treatments $[30,49,69,97]$.

Short stature is characteristic of patients with MPS, and is likely secondary to a combination of structural, metabolic, and endocrine abnormalities. The characteristic skeletal abnormalities of MPS (e.g. kyphoscoliosis and genu valgum) limit growth and adult height. However this does not entirely explain the short stature since it is found in children with MPS even without severe abnormal spine curvatures or genu valgum. The mechanism of poor growth in the different types of MPS is not entirely understood, but may also be related to abnormalities of the growth plate which include decreased matrix deposition with impaired osteoblast function, hypertrophic chondrocytes, disordered growth plate cellular structure, and GAG accumulation in the growth plate (Fig. 1) $[1,57,66,78,84]$. Bone formation has been shown to improve in the feline model of MPS VI when treated with ERT in a dose dependent manner [20], however no data are available in humans.

We have previously shown a very high prevalence of later growth failure in children with MPS IH treated with HCT suggesting a lack of penetration of enzyme 

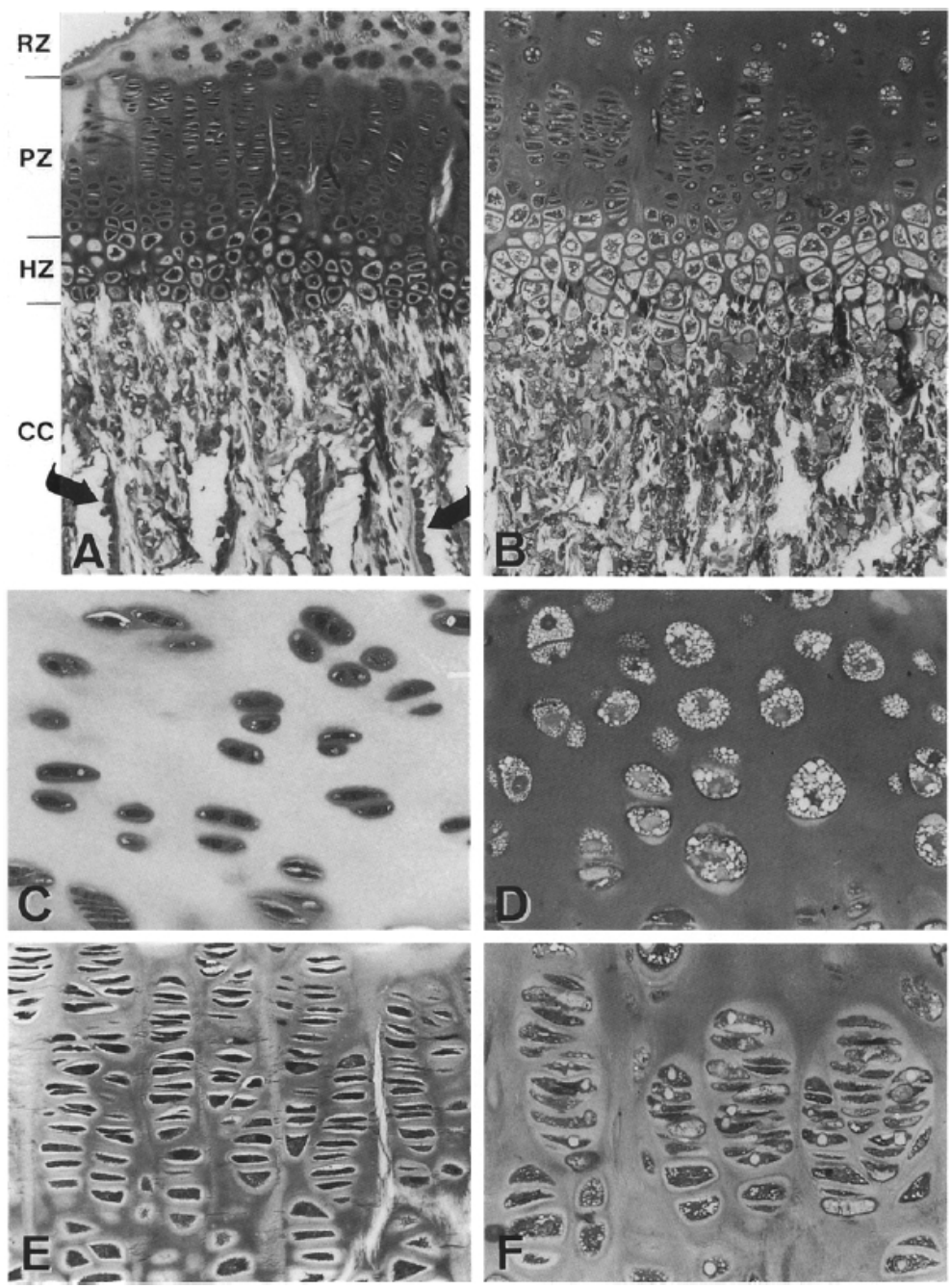

Fig. 1. (A) A longitudinal histological section of a decalcified epiphyseal growth plate from a control cat with clearly defined growth zones. In the calcified cartilage zone, osteoblasts line the trabecule (arrows). RZ (resting zone), PZ (proliferative zone), HZ (hypertrophic zone), CC (calcified cartilage). Magnification $\times 150$. (B) A midline longitudinal histological section of a decalcified epiphyseal growth plate from a cat with MPS VI. Note that the different zones are distinguishable, but there are clear differences in the organization and structure of tissue and cells compared with the control cat of A. There is a disruption of the proliferate zone, and a loss of columnation of the hypertrophic zone. Magnification $\times 150$. (C) A higher magnification of normal chondrocytes in the resting zone of the control cat of A. Magnification $\times 400$. (D) A higher magnification of the resting zone of an MPS VI-affected animal. Note the larger, swollen, vacuolated cells with clumped cytoplasm that is separated from the plasma membrane, and indistinct nucleus. Magnification $\times 400$. (E) A higher magnification of the proliferative zone of a control animal. Note the well-defined columns with an even height and number of cells. Individual cells have some normal degree of flatness with internal spaces filled with cytoplasm, and a clearly distinguishable nucleus. Magnification (F) A higher magnification of the proliferative zone of an MPS VI cat. The columns are poorly organized, with fewer cells per column. Note the flattened cells showing a condensed cytoplasm separated from the plasma membrane, and an indistinct nucleus. Magnification $\times$ 400. (From Abreu et al. Growth Plate Pathology in Feline Mucopolysaccharidosis VI. Calcif Tissue Int. 57 (1995), 185-190, with permission.).

into the growth plate [69]. In addition, the skeletal and joint abnormalities have also been shown to persist and even worsen with time since HCT $[30,97]$. Lysosomal GAG accumulation has been documented in the pituitary gland, thyroid gland, and testes of children with MPS II $[64,67]$, and in ovarian tissue of a murine model of MPS VII [86]. Growth hormone, thyroid hormone, and sex steroids (estrogen, testosterone) are all critical for normal growth and development. Low insulin-like growth factor-1 (IGF-1) levels have been reported in three brothers with MPS II [90]. Precocious puberty has been described in MPS IIIA [91], and we described hypothyroidism, growth hormone (GH) deficiency, low IGF-1, and precocious puberty in children with MPS 
IH after HCT [69]. Precocious puberty may be related to hypothalamic or pituitary damage, in particular after total body irradiation (TBI) used prior to HCT, and is particularly detrimental to adult height due to a rapid closure of the growth plates. In summary, current literature suggests that pituitary dysfunction, hypothyroidism, low IGF-1 and GH, and pubertal disruption may be associated with MPS in some cases, and therefore may contribute to the short stature.

A child's growth is one of the best indicators of overall health and it can be impacted by poor nutrition, insufficient growth or thyroid hormones, abnormal bone metabolism, chronic disease, and social isolation. For children with skeletal dysplasias, or other syndromes affecting height, it is important to know the natural history of growth. As in otherwise healthy children, these expected growth patterns provide a measure of health, and a measure to which new treatments can be compared. Expected growth can also help families make individualized decisions about growth promoting treatment options. Short stature in MPS can be quite severe, frequently -3 to -6 standard deviations below the mean height for age and gender. Short stature this severe limits activities of daily living, and can negatively impact social development, socio-economic status, and career advancement [33,74,103]. This article will review the current published data on growth in children with MPS, and describe preliminary data on the potential use of human growth hormone $(\mathrm{hGH})$ in children with MPS.

\section{Growth}

\subsection{MPS I}

\subsubsection{Growth in MPS I after HCT}

Hurler syndrome, or mucopolysaccharidosis type IH (MPS IH), is an autosomal recessive, lysosomal storage disease caused by deficiency of alpha-L-iduronidase, an enzyme which is required for the breakdown of the glycosaminoglycans (GAG) heparan and dermatan sulfate [9]. Clinically, MPS IH is characterized by short stature, coarse facies, cognitive and gross motor delays, corneal clouding, dysostosis multiplex, cardiac manifestations, and hepatosplenomegaly $[8,27,65,68,98]$. Dysostosis multiplex is a constellation of skeletal abnormalities including kyphosis, scoliosis, hip dysplasia, and genu valgum. MPS IH is typically diagnosed in patients less than two years of age.
Without treatment, children with MPS IH typically die by 10 years of age due to cardiac or respiratory complications $[65,98]$. Currently, most children with MPS IH are treated with HCT [23,36,50,87,94]. HCT as an intervention, however, compounds the problem of short stature. HCT has been associated with growth suppression, growth hormone deficiency, abnormal gonadal and thyroid function, and damage to the epiphyseal growth plate, pituitary gland and hypothalamus $[10,11,18,31,32,43,52,73,82]$, all potential causes of short stature. With HCT, children with MPS $\mathrm{IH}$ are living into their adult years and therefore determining long-term outcomes and complications has become clinically important. Early diagnosis and replacement of hormonal deficiencies are critical for optimizing growth and development. While many studies have examined long-term growth for other conditions following HCT [18,31,32,43,52,73,82], there are few growth data specific to patients with MPS IH children after HCT [69,87,94].

Polgreen et al. found a prevalence of short stature in children with MPS IH after HCT to be $71 \%$ at the most recent evaluation. The growth patterns for both genders demonstrated a progressive falling behind relative to the $\mathrm{CDC}$ reference data (Fig. 2). Later age at HCT and exposure to TBI were associated with an increased prevalence of short stature. By 10 years of age, mean height SD decreased to $-3.2 \pm 1.6 \mathrm{SD}$ and the prevalence of short stature increased to $87 \%$ ( $n=13$ of 15). Short stature was diagnosed in $46 \%$ of children who had a cord blood donor, $72 \%$ and $88 \%$ (related and unrelated, respectively) of children who received bone marrow. This seems to suggest improved growth in children treated with cord blood HCT; however this difference was compounded by the fact that the length of follow up was shorter in these children compared to those with other donor sources. This association was not statistically significant when adjusting for the age at last height evaluation. The prevalence of short stature in children with MPS IH after HCT was quite high compared to that found in other studies of patients who received HCT for conditions other than MPS IH [11, 52,82 ]; $14-31 \%$ of patients in these reports had short stature at last follow-up, compared to $71 \%$ with short stature in MPS IH patients.

Progressive growth failure in children with MPS IH after HCT was also reported by Vellodi et al. [94]. They found that the mean height fell beneath the normal range for age around 8 year of age. They also measured sitting heights and leg lengths; their data suggested that the decrease in sitting height accounted for the majority 


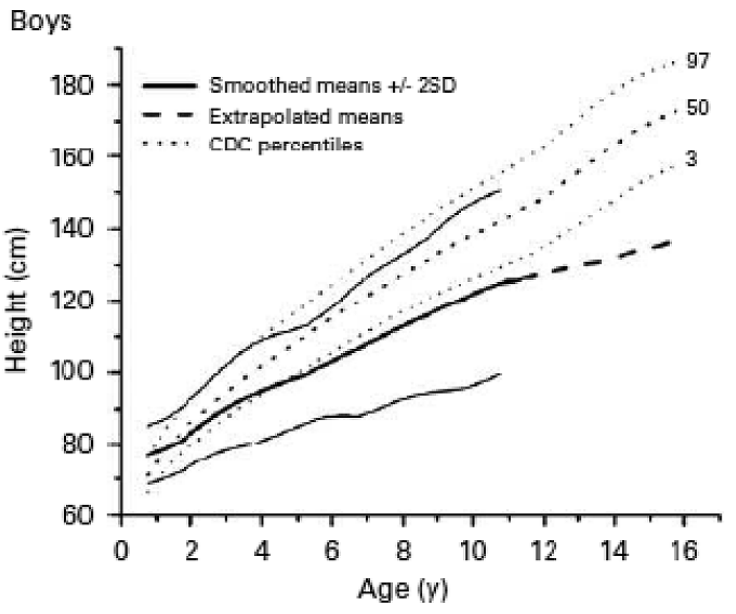

(a)

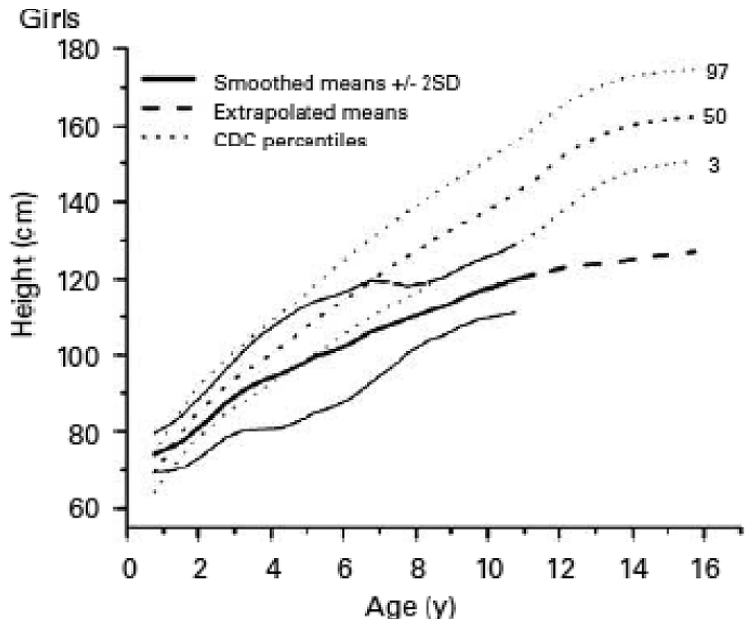

(b)

Fig. 2. Growth patterns of boys (a) and girls (b) from time of hematopoietic stem cell transplantation (HSCT) to time of last follow-up visit superimposed on standard Centers for Disease Control and Prevention (CDC) percentiles for height by age. (From Polgreen et al. Growth and endocrine function in patients with Hurler syndrome after hematopoietic stem cell transplantation, BMT 41 (2008), 1005-1011, with permission).
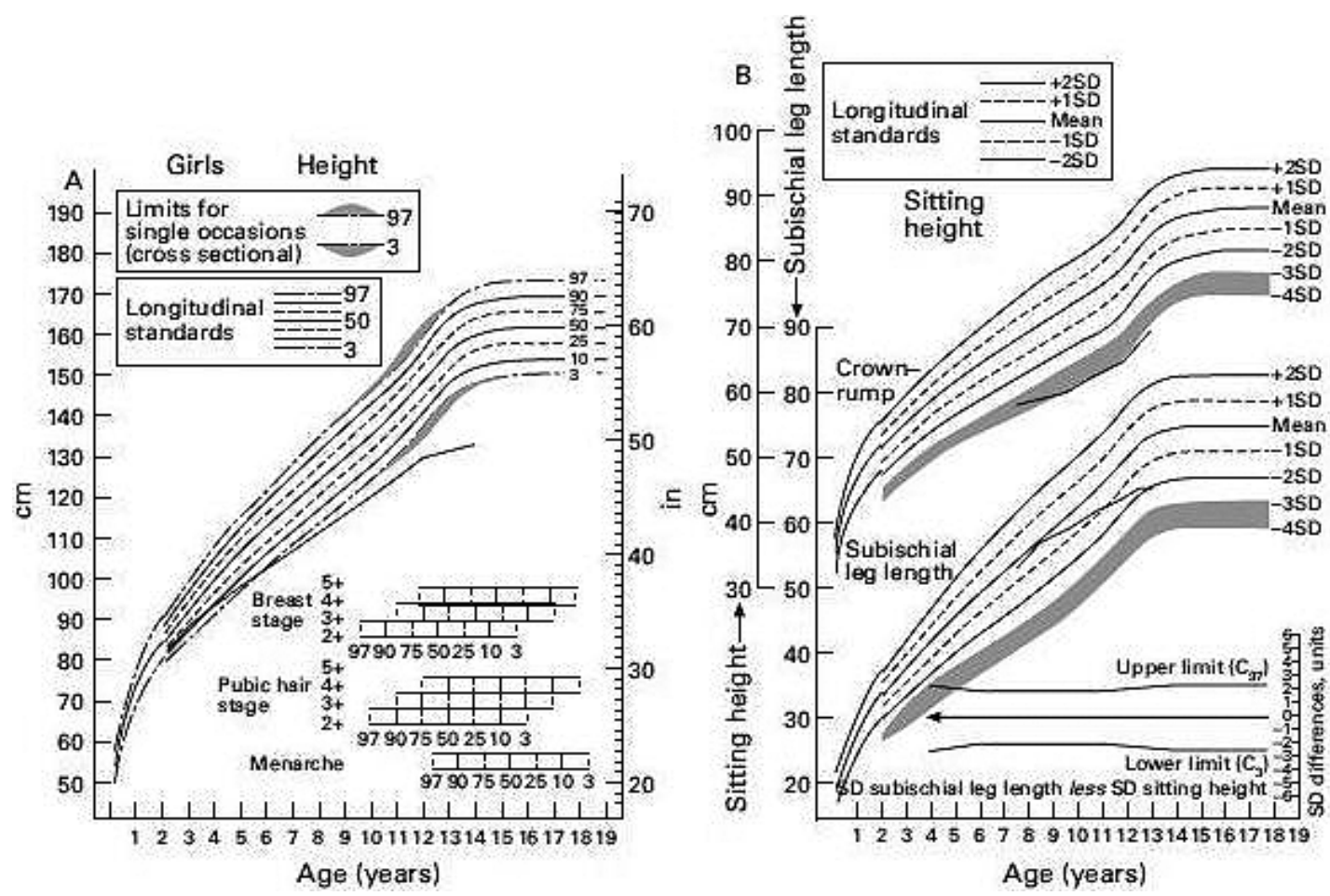

Fig. 3. Linear growth chart showing gradual falling off of height (A) and sitting height and subischial leg length: note the relative position of the latter (B). (From Vellodi et al. Bone marrow transplantation for mucopolysaccharidosis type I: experience of two British centres. Arch Dis Child 76 (1997), 92-99, with permission.).

of decreasing growth velocity. Although total body irradiation (TBI) has been associated with poor spine growth [40,54], only 1 subject in the study by Vellodi et al. had received TBI. Therefore, it appears to be the persistence of MPS skeletal disease which resulted in the decreased sitting height.

Another study of outcomes in MPS IH after HCT was published by Staba et al. [87] They found normal 
Table 1

Height and weight growth. (From Sifuentes et al. A follow-up study of MPS I patients treated with laronidase enzyme replacement therapy for 6 years. Molecular Genetics and Metabolism 90 (2007), 171-180, with permission.)

\begin{tabular}{|c|c|c|c|c|c|c|c|c|}
\hline \multirow[t]{2}{*}{ Patient $\mathrm{Na}$} & \multicolumn{4}{|c|}{ Height $(\mathrm{cm})$} & \multicolumn{4}{|c|}{ Weight (kg) } \\
\hline & Year 0 & Year 2 & Year 6 & $\%$ Increase & Year 0 & Year 2 & Year 6 & $\%$ Increase \\
\hline $003^{\mathrm{a}}$ & 122.5 & 134.0 & 162.9 & 33.0 & 27.0 & 34.4 & 56.7 & 110.0 \\
\hline $004^{\mathrm{a}}$ & 125.0 & 137.0 & 156.7 & 25.4 & 34.6 & 48.4 & 73.8 & 113.3 \\
\hline $005^{\mathrm{a}}$ & 127.0 & 143.7 & 154.4 & 21.6 & 24.4 & 35.2 & 47.0 & 92.6 \\
\hline 007 & 160.0 & 160.4 & 161.1 & 0.7 & 57.2 & 61.4 & 66.4 & 16.1 \\
\hline 010 & 160.0 & 159.7 & 160.4 & 0.3 & 54.6 & 63.4 & 65.6 & 20.2 \\
\hline Overall Mean $^{\text {b }}$ & $138.9(124.8)$ & $147.0(138.2)$ & $159.1(158.0)$ & $16.2(26.6)$ & $39.6(28.7)$ & $48.6(39.3)$ & $61.9(59.2)$ & $70.4(105.3)$ \\
\hline
\end{tabular}

Individual data are shown for growth at baseline, 2 years and 6 years of treatment. The pre-pubertal patients 003 , 004 and 005 grew $26.6 \%$ during this period whereas the older post-pubertal patients did not grow. Weight increased more than proportionally with the same pre-pubertal patients gaining $105.3 \%$ in weight. Comparison of individuals show a consistent pattern of growth over the 6-year period. Prior work had shown an increase in growth rate in the first year on therapy [45].

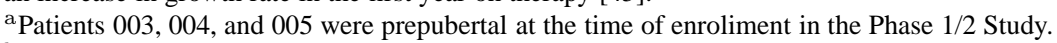

${ }^{\mathrm{b}}$ Means shown in parentheses are for the 3 patients who were prepubertal at Baseline.

growth velocity for $1-4$ years after cord blood HCT in 6 children with MPS IH, less than 7 years of age at the last follow-up, and speculated that possibly cord blood HCT resulted in improved growth after HCT. However, in the study by Polgreen et al. [69] this association was lost with increased length of follow-up. Therefore the finding by Staba et al. may be influenced by the relatively short follow up period. Currently, there are insufficient long-term data to draw definitive conclusions about the impact of donor type (stem cells versus marrow) on growth, or the expected final adult height in this population.

\subsubsection{Growth in MPS I during ERT}

Growth has also been evaluated in children with MPS I who were treated with ERT by Kakkis et al. [45]. They found that after 1 year of treatment with ERT, growth velocity increased significantly from a mean growth velocity of $2.8 \mathrm{~cm} / \mathrm{yr}$ to $5.2 \mathrm{~cm} / \mathrm{yr}$, an increase that is considered significant in the pediatric growth hormone literature. Individual increase in growth velocity after 1 year of treatment with ERT ranged from $0.9 \mathrm{~cm} / \mathrm{yr}$ to $5.1 \mathrm{~cm} / \mathrm{yr}$.

Long-term follow up of the impact of ERT on growth in MPS I by Sifuente et al. [83] found a much greater improvement in growth velocity in children with MPS I who were prepubertal compared to those who were pubertal (Table 1). The three children in this study who were prepubertal at the initiation of ERT increased their height on average by $27 \%$, compared to those who were pubertal and only increased height by $0.5 \%$. This suggests that earlier initiation of ERT may result in improved adult height; however the number of patients was small and no long term data are currently available to confirm this. Ongoing skeletal disease and development of pituitary insufficiencies may ultimately limit height potential unless new treatments for bone disease are developed, and early detection of endocrine disease is established in routine clinical care.

\subsection{MPS II}

Hunter Syndrome (MPS II) has generally less severe clinical features compared to MPS I. The characteristic clinical findings of MPS II are coarse features, dysostosis multiplex with severe short stature, valvular heart disease, deafness, and hepatosplenomegaly [65,101]. There are two forms of Hunter syndrome, MPS IIA and MPS IIB. MPS IIA is more severe and is characterized by progressive mental deterioration and death by the mid teens. MPS IIB is the milder form, characterized by minimal mental deterioration and survival into adulthood. Children with Hunter syndrome treated with ERT [60] seem to have improved mobility, pulmonary function, and energy level, and decrease hepatosplenomegaly [60,101].

Young et al. found that in 31 cases of mild Hunter syndrome growth velocity began to decline significantly around age 4 years resulting in short stature in $100 \%$ of the children by age 12 years (Fig. 4). No data have yet been published on growth in children with MPS II treated with ERT.

\subsection{MPS III}

Sanfilippo syndrome (MPS III) results from impaired degradation of heparan sulfate [29]. MPS III has four forms and is distinguished from the other MPS syndromes by the severity of CNS disease. The only published data on growth in MPS III is from Vellodi et al. who reported the response to treatment with HCT in two twin sisters with MPS III [93]. Their report 


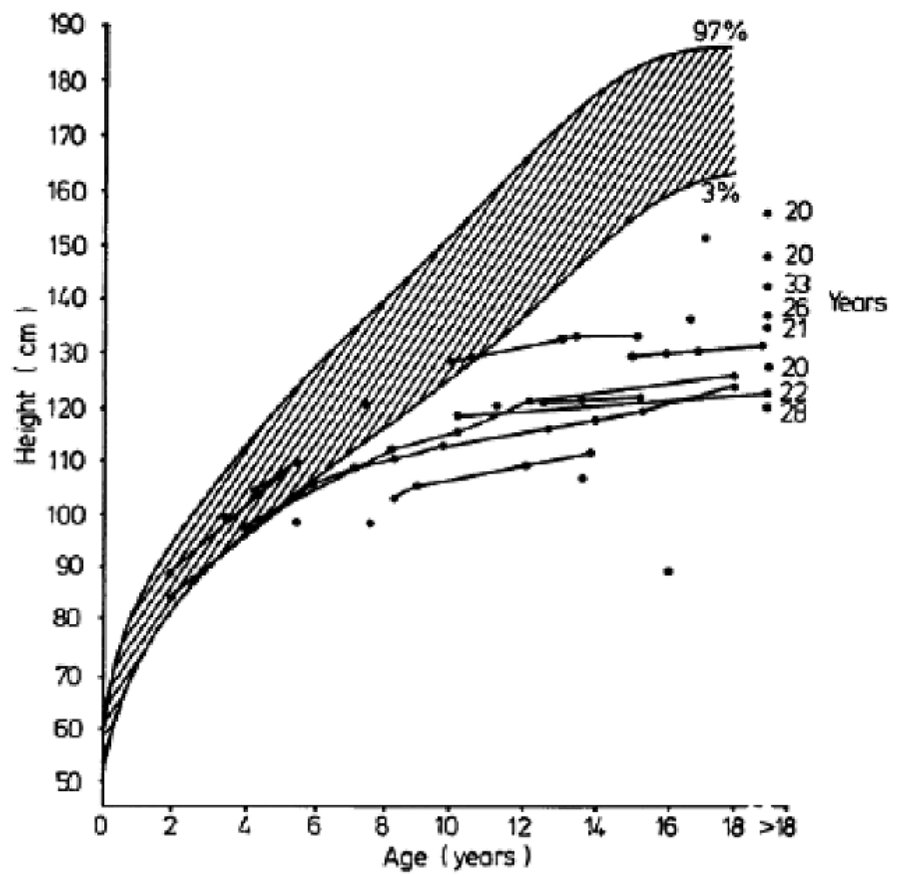

Fig. 4. Linear growth in study patients. (From Young and Harper. Mild form of Hunter's syndrome: clinical delineation based on 31 cases. Arch Dis Child 57 (1982), 828-836, with permission.)

followed these twin girls for 9 years after HCT and showed periods of normal growth, with periods of decreased growth. ERT is not currently available for MPS III. There are no published growth data on untreated children with MPS III.

\subsection{MPS IV}

The International Morquio Organization Registry has accumulated a wealth of data, including growth data, in MPS IV. Morquio syndrome (MPS IV) is caused by the accumulation of keratan sulfate which results in skeletal dysplasia and short stature [59]. There are two described forms of Morquio syndrome - types A and B. Type A is most severe form. The majority of data are for type A. Montano et al. published registry results of growth in 312 children and adults with Morquio type A [59]. They found progressive growth failure in children with Morquio type A. The mean adult height for men was $122.5 \pm 22.5 \mathrm{~cm}$ and for women was $116.5 \pm$ $20.5 \mathrm{~cm}$. This is significantly shorter than the mean adult height for men and women based on the CDC reference data $(176.2 \mathrm{~cm}$ and 163.1 respectively).

Montano et al. went on to publish growth data from 354 patients with Morquio A, using a questionnairebased longitudinal and cross sectional design [58]. They found that the mean length/height in an infant and young child with Morquio A was similar to that of the normal population, however around 4 years of age the mean height fell below the normal range $(<-2$ SDS $)$ and there was progressive growth failure. This is earlier than that found in children with MPS IH and MPS II. The subjects in this study reached their final adult height at 11 years for males and 9 years for females.

\subsection{MPS VI}

The clinical features of Maroteaux-Lamy syndrome (MPS VI) vary in severity but resemble MPS I and II with short stature, hepatosplenomegaly, dysostosis multiplex, cardiac abnormalities, and characteristic facial features. Contrary to MPS I and II, cognitive functioning in MPS VI is typically normal. MPS VI is treated with ERT which has been shown to be safe, improve mobility and endurance, and decrease urine GAG levels $[38,39]$. However, there are currently no reports of growth either before or during ERT in MPS VI.

\section{Growth hormone}

\subsection{Growth impact of human growth $h G H$}

Recombinant hGH has been shown to be safe and effective for the treatment of short stature in various pop- 
ulations, including GH deficiency, small for gestational age (SGA), Turner syndrome, Noonan syndrome, children receiving long-term glucocorticoid therapy, chronic renal insufficiency, SHOX deficiency and Leri-Weill, Prader-Willi syndrome, and idiopathic short stature [5, $15,42,56,57,64,73,88,95]$. HGH has been used to treat short stature in certain populations of children with skeletal dysplasias with variable results $[4,13,19,37,46$, $48,72,88]$. There has been concern that hGH may worsen skeletal disproportions in skeletal dysplasias; however, the reports of worsening disproportionality appear to be exclusive to children with achondroplasia $[19,72$, $88]$.

\subsection{Skeletal impact of $h G H$}

Although there are potential orthopedic complications of treatment with hGH, hGH has been shown to have beneficial skeletal and bone composition effects which may outweigh these concerns. Treatment with hGH has been shown to increase total body, lumbar, and femoral neck BMD and BMD Z-scores by DXA, decrease body fat percentage, and improve peak bone mass accrual $[2,3,12,34,35,47,79,100]$. A study by Lanes et al. showed an increase in lumbar spine BMD by DXA in children with idiopathic short stature (not GH deficient), who were treated with hGH [51]. This improved BMD gain is likely mediated though the increased production of insulin-like growth factor1 (IGF-1) which has been shown in both humans and animal models to stimulate bone turnover in favor of bone formation resulting in increased BMD [3,25,28, 53,102]. GH does not appear to directly stimulate chondrocyte proliferation, rather stimulation is via IGF1 [44].

A potential adverse effect of treatment with hGH is worsening of scoliosis and kyphosis, which are characteristic of MPS. Although it is generally thought that any growth has the potential to worsen scoliosis [26, 37 , there is no clear conclusion in the literature regarding the impact of hGH on the prevalence or progression of scoliosis or kyphosis. While some researchers have found a higher than expected percentage and rate of curve progression [96], others have observed little to no progression attributable to hGH therapy [2,24,71,95]. Populations with an increased baseline prevalence of scoliosis include children with Turner syndrome (TS), or Prader-Willi syndrome (PWS). Both of these populations have been studied for the impact of $\mathrm{hGH}$ on scoliosis. Bolar et al. found that in girls with TS treated with hGH, $44 \%$ had progression of scoliosis, and $69 \%$ of those were considered non-serious progression [14]. The PWS study by Nagai et al., monitored scoliosis in $20 \mathrm{hGH}$-treated patients with PWS and observed progression in six, fluctuation in one, improvement in three, and no change in ten. There was no significant difference between the incidence of scoliosis in hGHtreated and untreated groups [63].

While there are reasons to think hGH therapy might benefit the bone disease in children with MPS, there is the possibility that they will not be able to respond to this therapy. Children with MPS may be resistant to hGH due to characteristic abnormalities of chondrocyte proliferation and accumulation of lysosomal storage material in the growth plate which have been documented in mice with MPS diseases [57,84]. In addition, it has been hypothesized that those children who are treated with HCT and irradiation may have local resistance to $\mathrm{hGH}$ due to damage of the growth plate by irradiation.

\subsection{Other potential benefits of $h G H$}

GH has been found to have other beneficial effects besides the impact on growth and bone. In patients who are GH deficient, a recent meta-analysis of 11 studies including 268 adult patients found that treatment with hGH improved exercise performance [99]. Treatment with hGH has also been shown to increase muscle mass and decrease fat mass in children who were born SGA, and those with PWS or TS, as well as increase pulmonary function in children with PWS $[6,61,62,80,81$, 100].

Various clinical trials of hGH have looked at the potential role of hGH in neuropsychological development/function. One study by Hokken-Koelega et al. found an improvement in performal and total IQ, problem behavior, and self perception in children who were SGA who were treated with hGH for 2-8 years [42]. Myers et al. reported an improvement in both language and cognitive functioning in children with PWS who were treated with hGH for 1 year compared to untreated children with PWS [62]. In addition, Arwert et al. studied patients with childhood onset hGH deficiency and found an improvement in both long-term and working memory after 6 months of treatment with hGH [7]. In contrast to the findings by Rovet et al. [77] and the above studies, Ross et al. did not find any difference in neurocognitive functioning in girls with Turner syndrome who were treated with hGH compared to those who were not [76]. Children with $18 \mathrm{q}$ deletion syndrome, a syndrome with significant developmental de- 


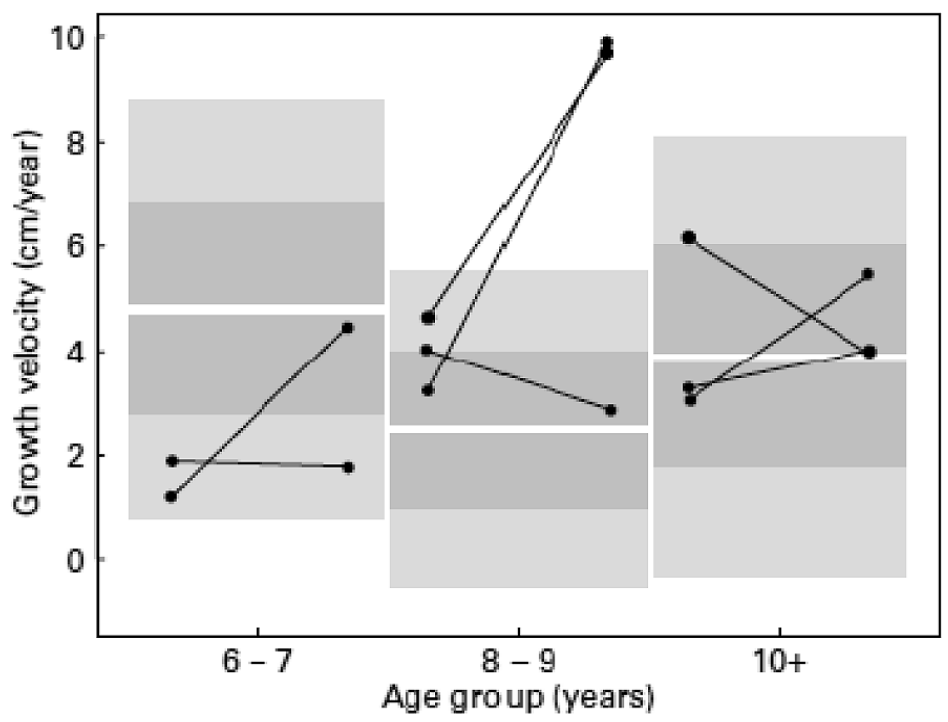

Fig. 5. Growth velocity before and after 1 year of treatment with GH for eight children with MPS IH. Each child is represented by a pair of connected points: the left point is growth velocity before treatment with $\mathrm{GH}$ and the right point is growth velocity1 year later. The size of the point is proportional to the dose of GH (ranging from 0.26 to $0.45 \mathrm{mg} / \mathrm{kg} / \mathrm{week}$ ). The eight children are shown, within their age group (6-7 years, 8-9 years, 10 years and older) against reference levels for growth velocity mean (white horizontal lines) and 2 s.d. (gray rectangles) calculated from 48 children with MPS IH after HCT not treated with GH. GH=growth hormone; MPS IH=mucopolysaccharidosis type IH. (From Polgreen et al. Short-term growth hormone treatment in children with Hurler syndrome after hematopoietic cell transplantation. BMT. 2009; Mar 2: Epub ahead of print, with permission.)

lays, were found to have an improvement in nonverbal IQ after an average of 37 months of treatment with hGH [21]. The extent of the impact of hGH on neuropsychological functioning is yet to be fully defined, as some studies have also found no impact of hGH in these areas [75].

\subsubsection{MPS I}

There is currently one published study on the use of hGH in children with any MPS disease [70]. In this study, we described a retrospective review of hGH treatment in 8 children with MPS IH after HCT. The objectives of the study were to begin to examine (1) whether hGH treatment improved growth velocity in 8 children with MPS IH, and (2) the impact of hGH on skeletal abnormalities in these children.

Baseline growth velocity was $3.5 \pm 1.5 \mathrm{~cm} / \mathrm{yr}$ $(-2.6 \pm 1.9 \mathrm{SDS})$ and increased to $5.2 \pm 3.0 \mathrm{~cm} / \mathrm{yr}$ $(-0.1 \pm 3.6$ SDS $)$ after 1 year of treatment. Growth velocities before and after 1 year of treatment with hGH are shown in comparison to the mean (SD) growth velocity in age-matched children with MPS IH after HCT not treated with hGH in Fig. 5.

To explore the impact of total body irradiation (TBI) on growth, we compared children treated with hGH to historical controls matched for age and TBI status.
A history of TBI was associated with lower mean increases in growth velocity, by about the same amount in both treated and untreated children. HGH treatment increased growth velocity on average regardless of TBI status.

In addition to the growth response, we also examined the skeletal impact of treatment with hGH in these children and found one child developed slipped capital femoral epiphysis (SCFE) approximately 6 months after orthopedic surgery on the same femur which resulted in discontinuation of hGH treatment. This is a known complication of hGH; however the orthopedic manipulation may have increased her risk for this complication, as well as her history of TBI. Of 6 patients with radiographic data there was 1 progression of scoliosis, 1 progression of kyphosis, and 1 progression of genu valgum. No patient discontinued treatment due to progression of skeletal disease.

\subsubsection{MPS II}

There are no published data on the safety or efficacy of hGH in children with MPS II. The following is the experience of our clinical practice with hGH treatment in two boys with MPS II. Both boys were started on a low dose of hGH, due to the unknown change in risk for intracranial hypertension with hGH treatment, with 
the intent of slowly increasing the dose to obtain full growth benefit.

Patient one is an 8 year old boy who was started on ERT at 5 years of age. Poor growth and a low IGF-1 prompted growth hormone stimulation testing for GH deficiency when he was 7 years old. The peak GH by arginine-clonidine stimulation testing previously described [69] was $6.6 \mu \mathrm{g} / \mathrm{L}$ which is an insufficient response and diagnostic of GHD [22]. Due to the unknown risk in intracranial hypertension in children with MPS II treated with hGH, a lower than standard dose of hGH was started $(0.1 \mathrm{mg} / \mathrm{kg} / \mathrm{wk})$. Growth velocity prior to initiation of treatment was $2.7 \mathrm{~cm} / \mathrm{yr}$, increased to $10.3 \mathrm{~cm} / \mathrm{yr}$ after 6 months, and then decreased to $3.4 \mathrm{~cm} / \mathrm{yr}$ after 12 months. Bone age (BA) was 4 years at chronologic age (CA) 7 years 8 months and 4 years 6 months when he was 8 years 3 months indicating a delayed bone age with normal bone age advancement during treatment with hGH. The IGF-1 level improved with treatment, but remained low suggesting insufficient hGH dose. He had no adverse effects of hGH during 1 year of treatment.

Patient two is a 4 year old boy who was started on ERT at 18 months of age. Poor growth and low IGF1 prompted screening for GHD when he was 3 years old. Arginine-clonidine stimulation testing revealed a borderline response $(9.6 \mu \mathrm{g} / \mathrm{L})$. Given the poor growth (growth velocity $0 \mathrm{~cm} / \mathrm{yr}$ ) and borderline response to stimulation testing, hGH was started at $0.1 \mathrm{mg} / \mathrm{kg} / \mathrm{wk}$. Growth velocity after 3 months of treatment had increased to $14.2 \mathrm{~cm} / \mathrm{yr}$, and after 6 months was $7.6 \mathrm{~cm} / \mathrm{yr}$. Bone age was 3 years at chronologic age 3 years 9 months, and 3 year 6 months at chronologic age 4 years 3 months. This is a normal bone age and normal advancement of bone age during treatment with hGH. IGF-1 improved with treatment, but remained low, once again suggesting insufficient dosing of hGH. He had no adverse effects of hGH during 6 months of treatment except for some moderate pain in the knees and lower legs.

\subsubsection{MPS IV}

There are no published data on the safety or efficacy of hGH in children with MPS IV. The following is the experience of our clinical practice with hGH treatment in two girls with MPS IV.

Patient one is a 17 year 6 month old female who was referred for poor growth and delayed puberty. Baseline growth velocity was $0.3 \mathrm{~cm} / \mathrm{yr}$ at 15 years 6 months. IGF-1 level was very low, however stimulated GH level was normal at $22.6 \mu \mathrm{g} / \mathrm{L}$. She was started on hGH at a dose of $0.3 \mathrm{mg} / \mathrm{kg} / \mathrm{wk}$. After 12 months of treatment, growth velocity increased to $2.7 \mathrm{~cm} / \mathrm{yr}$, and in year two of treatment growth velocity was $1.9 \mathrm{~cm} / \mathrm{yr}$. Her bone age was 7 months 10 months at chronologic age 15 years 6 months and then 13 years at chronologic age 17 years 4 months after 6 months of estrogen replacement therapy. Estrogen replacement was initiated in year two of hGH treatment for treatment of delayed puberty. She experienced no adverse side effects, including no significant progression of kyphoscoliosis. Bone mineral density (BMD) was evaluated by DXA at the end of year 1 and year 2 of hGH treatment. In this period of time, BMD increased by $13.6 \%$ and $5.7 \%$ for lumbar spine and total body respectively. BMD $\mathrm{Z}$-score adjusted by height age increased from -2.2 to -1.2 for lumbar spine and from -0.3 to +0.9 for total body. Initiation of estrogen replacement likely accounts for some of this improvement, in addition to treatment with hGH.

Patient two is a 13 year old female also referred for poor growth and delayed puberty. Baseline growth velocity was $0 \mathrm{~cm} / \mathrm{yr}$ at the age of 11 years. IGF- 1 was also very low, and her peak stimulated GH level was normal $(11 \mu \mathrm{g} / \mathrm{L})$. She was started on $\mathrm{hGH}$ at $0.3 \mathrm{mg} / \mathrm{kg} / \mathrm{wk}$. hGH dose was increase to $0.36 \mathrm{mg} / \mathrm{kg} / \mathrm{wk}$ after months of treatment and then continued at this dose. After 12 months of treatment growth velocity increased to $4.7 \mathrm{~cm} / \mathrm{yr}$, and in year 2 of treatment growth velocity was $2.3 \mathrm{~cm} / \mathrm{yr}$. Estrogen replacement was started after 2 years of treatment with hGH. Her bone age was 6 years 10 months at 11 years 11 months and 6 years 10 months at chronologic age 13 years 9 months. She experienced no adverse side effects, including no significant progression of kyphoscoliosis. BMD increased by $9.8 \%$ for lumbar spine and $4 \%$ for total body during year 2; Z-score adjusted by height age increased from -1.7 to -1.1 for lumbar spine and from +0.2 to +0.7 for total body.

\subsubsection{MPS VI}

One patient with MPS VI was treated with hGH in our practice. He was treated with ERT since the age of 7 years. This patient was started on hGH at the age of 12 years for short stature and decreased growth velocity. He was prepubertal by examination at that time. Growth hormone stimulation testing was normal. Baseline growth velocity was $2.3 \mathrm{~cm} / \mathrm{yr}$. Bone age was 9 years at 11 years 10 months. He was started on $\mathrm{hGH}$ at $0.4 \mathrm{mg} / \mathrm{kg} / \mathrm{wk}$; this dose was increased to $0.65 \mathrm{mg} / \mathrm{kg} / \mathrm{wk}$ over 3 years of treatment. At the end of year 1 growth velocity was $5.9 \mathrm{~cm} / \mathrm{yr}$ (Tanner stage was 
II); end of year 2 was $4 \mathrm{~cm} / \mathrm{yr}$ (Tanner stage was III); and end of year 3 was $4.1 \mathrm{~cm} / \mathrm{yr}$ (Tanner stage was IV). Bone age advancement was somewhat rapid with the bone age advancing 4 years over 3 years of treatment (BA 13 years at CA 14 years 10 months). Cervical spine stenosis was present and mildly progressive prior to hGH treatment. There was no significant progression by brain MRI during the 3 years of treatment; however the patient has had progression of clinical symptoms of cord compression including numbness and tingling in hands, and stable but persistent absence of sensory potentials and decreased median nerve compound potentials during EMG nerve conduction velocity testing after carpal tunnel release.

\section{Conclusions}

This review of the current literature on growth and growth hormone in MPS revealed that short stature due to progressive growth failure is common in all MPS diseases. Weight and length are often normal at birth, but then growth failure results in short stature by 48 years of age in most children with MPS. Growth failure may be the presenting sign and therefore MPS should be considered in children evaluated for short stature.

ERT and HCT have been successful in prolonging the life expectancy of children with MPS. Although there appears to be an initial improvement in growth with these treatments, most children with MPS regardless of treatment have impaired growth. The etiology of this persistent, impaired growth is currently not well defined. It may be related to a lack of penetration of the enzyme into skeletal and connective tissues, persistent osteoblast or chondrocyte dysfunction, or resistance to growth hormone. Hormone deficiencies, particularly after HCT, likely contribute to the poor growth as well.

Although preliminary data suggests a benefit for some children with MPS from hGH, there are currently insufficient data on the safety and efficacy of hGH in children with MPS to recommend it as a standard of care. Controlled clinical trials are needed to determine if hGH will provide children with MPS the same benefits in growth, muscle strength, bone health, pulmonary function, and neuropsychological functioning that have been reported in other pediatric populations.

Further research is needed into the long term outcomes of both HCT and ERT. Questions remaining include: 1) Do children treated with cord blood HCT versus marrow HCT have better growth? 2) Now that
TBI is rarely used in the preparatory regimens of HCT, are growth outcomes better? 3) What is the long term growth pattern of children treated with ERT and the best protocol for administration of ERT? In addition, translational studies are needed to better understanding the etiology of growth failure in MPS which would help guide future therapeutic interventions.

\section{Acknowledgements}

This publication was supported in part by NIH/NCRR Grant Number K12 RR023247. Its contents are the authors' sole responsibility and do not necessarily represent official NIH views.

This manuscript was developed as the result of a meeting of experts entitled "Promoting Bone Health in MPS VI: Framing New Therapies" held in Oakland, California in October, 2008. This meeting was supported by an educational grant from BioMarin Pharmaceutical, Inc., Novato, CA. BioMarin had no role in the content presented and discussed at the meeting. All authors participated in the development and writing of the manuscript and are fully responsible for its content.

\section{Conflicts of interest}

Dr. Polgreen has research support from Genentech. Dr. Miller has research support from Genentech, Pfizer, Norditropin, and Tercica, and is part of the speaker's bureau for Genentech, Pfizer, and Norditropin. However, the work presented in this manuscript was not supported by any of these growth hormone companies.

\section{References}

[1] S. Abreu, J. Hayden, P. Berthold, I.M. Shapiro, S. Decker, D. Patterson and M. Haskins, Growth plate pathology in feline mucopolysaccharidosis VI, Calcif Tissue Int 57 (1995), 185190.

[2] O. Ali, M. Shim, E. Fowler, M. Greenberg, D. Perkins, W. Oppenheim and P. Cohen, Growth hormone therapy improves bone mineral density in children with cerebral palsy: a preliminary pilot study, J Clin Endocrinol Metab 92 (2007), 932-937.

[3] O. Ali, M. Shim, E. Fowler, P. Cohen and W. Oppenheim, Spinal bone mineral density, IGF-1 and IGFBP-3 in children with cerebral palsy, Horm Res 68 (2007), 316-320.

[4] S. Appan, S. Laurent, M. Chapman, P.C. Hindmarsh and C.G. Brook, Growth and growth hormone therapy in hypochondroplasia, Acta Paediatr Scand 79 (1990), 796-803. 
[5] J. Argente, R. Gracia, L. Ibanez, A. Oliver, E. Borrajo, A. Vela, J.P. Lopez-Siguero, M.L. Moreno and F. RodriguezHierro, Improvement in growth after two years of growth hormone therapy in very young children born small for gestational age and without spontaneous catch-up growth: results of a multicenter, controlled, randomized, open clinical trial, J Clin Endocrinol Metab 92 (2007), 3095-3101.

[6] M. Ari, V.K. Bakalov, S. Hill and C.A. Bondy, The effects of growth hormone treatment on bone mineral density and body composition in girls with turner syndrome, J Clin Endocrinol Metab 91 (2006), 4302-4305.

[7] L.I. Arwert, D.J. Veltman, J.B. Deijen, P.S. van Dam and M.L. Drent, Effects of growth hormone substitution therapy on cognitive functioning in growth hormone deficient patients: a functional MRI study, Neuroendocrinology $\mathbf{8 3}$ (2006), 12-19.

[8] J.L. Ashworth, S. Biswas, E. Wraith and I.C. Lloyd, The ocular features of the mucopolysaccharidoses, Eye $\mathbf{2 0}$ (2006), 553-563.

[9] G. Bach, R. Friedman, B. Weissmann and E.F. Neufeld, The defect in the Hurler and Scheie syndromes: deficiency of alpha-L-iduronidase, Proc Natl Acad Sci USA 69 (1972), 2048-2051.

[10] B. Bakker, G.G. Massa, W. Oostdijk, M.H. Van WeelSipman, J.M. Vossen and J.M. Wit, Pubertal development and growth after total-body irradiation and bone marrow transplantation for haematological malignancies, Eur J Pediatr 159 (2000), 31-37.

[11] B. Bakker, W. Oostdijk, D. Bresters, M.J. Walenkamp, J.M. Vossen and J.M. Wit, Disturbances of growth and endocrine function after busulphan-based conditioning for haematopoietic stem cell transplantation during infancy and childhood, Bone Marrow Transplant 33 (2004), 1049-1056.

[12] G.I. Baroncelli, S. Bertelloni, C. Ceccarelli, D. Cupelli and G. Saggese, Dynamics of bone turnover in children with GH deficiency treated with GH until final height, Eur J Endocrinol 142 (2000), 549-556.

[13] G. Bocca, C.M. Weemaes, I. van der Burgt and B.J. Otten, Growth hormone treatment in cartilage-hair hypoplasia: effects on growth and the immune system, J Pediatr Endocrinol Metab 17 (2004), 47-54.

[14] K. Bolar, A.R. Hoffman, T. Maneatis and B. Lippe, LongTerm Safety of Recombinant Human Growth Hormone in Turner Syndrome, J Clin Endocrinol Metab (2007), jc.20071723.

[15] E.A. Braunlin, A.G. Rose, J.J. Hopwood, R.D. Candel and W. Krivit, Coronary artery patency following long-term successful engraftment 14 years after bone marrow transplantation in the Hurler syndrome, Am J Cardiol $\mathbf{8 8}$ (2001), 1075-1077.

[16] E.A. Braunlin, J.M. Berry and C.B. Whitley, Cardiac findings after enzyme replacement therapy for mucopolysaccharidosis type I, Am J Cardiol 98 (2006), 416-418.

[17] E.A. Braunlin, N.R. Stauffer, C.H. Peters, J.L. Bass, J.M. Berry, J.J. Hopwood and W. Krivit, Usefulness of bone marrow transplantation in the Hurler syndrome, Am J Cardiol 92 (2003), 882-886.

[18] B.M. Brennan and S.M. Shalet, Endocrine late effects after bone marrow transplant, Br J Haematol 118 (2002), 58-66.

[19] C.P. Burren and G.A. Werther, Skeletal dysplasias: response to growth hormone therapy, J Pediatr Endocrinol Metab 9 (1996), 31-40.

[20] S. Byers, J.D. Nuttall, A.C. Crawley, J.J. Hopwood, K. Smith and N.L. Fazzalari, Effect of enzyme replacement therapy on bone formation in a feline model of mucopolysaccharidosis type VI, Bone 21 (1997), 425-431.

[21] J.D. Cody, M. Semrud-Clikeman, L.J. Hardies, J. Lancaster, P.D. Ghidoni, R.L. Schaub, N.M. Thompson, L. Wells, J.E. Cornell, T.M. Love, P.T. Fox, R.J. Leach, C.I. Kaye and D.E. Hale, Growth hormone benefits children with $18 \mathrm{q}$ deletions, Am J Med Genet A 137 (2005), 9-15.

[22] Consensus guidelines for the diagnosis and treatment of growth hormone $(\mathrm{GH})$ deficiency in childhood and adolescence: summary statement of the GH Research Society. GH Research Society, J Clin Endocrinol Metab 85 (2000), 3990_ 3993

[23] J. Cox-Brinkman, J.J. Boelens, J.E. Wraith, A. O'Meara, P. Veys, F.A. Wijburg, N. Wulffraat and R.F. Wynn, Haematopoietic cell transplantation (HCT) in combination with enzyme replacement therapy (ERT) in patients with Hurler syndrome, Bone Marrow Transplant 38 (2006), 1721.

[24] G. Day, I. McPhee, J. Batch and F. Tomlinson, Growth rates and the prevalence and progression of scoliosis in shortstatured children on Australian growth hormone treatment programmes, Scoliosis 2 (2007).

[25] D.J. DiGirolamo, A. Mukherjee, K. Fulzele, Y. Gan, X. Cao, S.J. Frank and T.L. Clemens, Mode of growth hormone action in osteoblasts, J Biol Chem 282 (2007), 31666-31674.

[26] P.L. Docquier, M. Mousny, M. Jouret, C. Bastin and J.J. Rombouts, Orthopaedic concerns in children with growth hormone therapy, Acta Orthop Belg 70 (2004), 299-305.

[27] S.C. Dusing, D. Thorpe, A. Rosenberg, V. Mercer and M.L. Escolar, Gross motor abilities in children with Hurler syndrome, Dev Med Child Neurol 48 (2006), 927-930.

[28] M. Ernst and E.R. Froesch, Growth hormone dependent stimulation of osteoblast-like cells in serum-free cultures via local synthesis of insulin-like growth factor I, Biochem Biophys Res Commun 151 (1988), 142-147.

[29] S. Esposito, N. Balzano, A. Daniele, G.R. Villani, K. Perkins, B. Weber, J.J. Hopwood and P. Di Natale, Heparan Nsulfatase gene: two novel mutations and transient expression of 15 defects, Biochim Biophys Acta 1501 (2000), 1-11.

[30] R.E. Field, J.A. Buchanan, M.G. Copplemans and P.M. Aichroth, Bone-marrow transplantation in Hurler's syndrome. Effect on skeletal development, J Bone Joint Surg Br 76 (1994), 975-981.

[31] P. Frisk, J. Arvidson, J. Gustafsson and G. Lönnerholm, Pubertal development and final height after autologous bone marrow transplantation for acute lymphoblastic leukemia, Bone Marrow Transplantation 33 (2004), 205-210.

[32] G. Giorgiani, M. Bozzola, F. Locatelli, P. Picco, M. Zecca, M. Cisternino, S. Dallorso, F. Bonetti, G. Dini, C. Borrone et al., Role of busulfan and total body irradiation on growth of prepubertal children receiving bone marrow transplantation and results of treatment with recombinant human growth hormone, Blood 86 (1995), 825-831.

[33] S.E. Gollust, R.E. Thompson, H.C. Gooding and B.B. Biesecker, Living with achondroplasia in an average-sized world: an assessment of quality of life, Am J Med Genet A 120A (2003), 447-458.

[34] E.N. Gonc and N. Kandemir, Long-term effects of growth hormone $(\mathrm{GH})$ on bone mineral status and bone turnover markers in patients with isolated GH deficiency and multiple pituitary hormone deficiency, Clin Endocrinol (Oxf) 66 (2007), 672-677.

[35] G. Gotherstrom, B.A. Bengtsson, I. Bosaeus, G. Johannsson and J. Svensson, Ten-year GH replacement increases bone mineral density in hypopituitary patients with adult onset $\mathrm{GH}$ 
deficiency, Eur J Endocrinol 156 (2007), 55-64.

[36] S.S. Grewal, R. Wynn, J.E. Abdenur, B.K. Burton, M. Gharib, C. Haase, R.J. Hayashi, S. Shenoy, D. Sillence, G.E. Tiller, M.E. Dudek, A. van Royen-Kerkhof, J.E. Wraith, P. Woodard, G.A. Young, N. Wulffraat, C.B. Whitley and C. Peters, Safety and efficacy of enzyme replacement therapy in combination with hematopoietic stem cell transplantation in Hurler syndrome, Genet Med 7 (2005), 143-146.

[37] D. Harada, Y. Yamanaka, K. Ueda, J. Shimizu, M. Inoue, Y. Seino and $\mathrm{H}$. Tanaka, An effective case of growth hormone treatment on cartilage-hair hypoplasia, Bone 36 (2005), 317 322.

[38] P. Harmatz, R. Giugliani, I. Schwartz, N. Guffon, E.L. Teles, M.C. Miranda, J.E. Wraith, M. Beck, L. Arash, M. Scarpa, Z.F. Yu, J. Wittes, K.I. Berger, M.S. Newman, A.M. Lowe, E. Kakkis and S.J. Swiedler, Enzyme replacement therapy for mucopolysaccharidosis VI: a phase 3, randomized, doubleblind, placebo-controlled, multinational study of recombinant human $\mathrm{N}$-acetylgalactosamine 4-sulfatase (recombinant human arylsulfatase B or rhASB) and follow-on, open-label extension study, J Pediatr 148 (2006), 533-539.

[39] P. Harmatz, R. Giugliani, I.V. Schwartz, N. Guffon, E.L. Teles, M.C. Miranda, J.E. Wraith, M. Beck, L. Arash, M. Scarpa, D. Ketteridge, J.J. Hopwood, B. Plecko, R. Steiner, C.B. Whitley, P. Kaplan, Z.F. Yu, S.J. Swiedler and C. Decker, Long-term follow-up of endurance and safety outcomes during enzyme replacement therapy for mucopolysaccharidosis VI: Final results of three clinical studies of recombinant human N-acetylgalactosamine 4-sulfatase, Mol Genet Metab 94 (2008), 469-475.

[40] K.A. Hartley, C. Li, F.H. Laningham, M.J. Krasin, X. Xiong and T.E. Merchant, Vertebral body growth after craniospinal irradiation, Int J Radiat Oncol Biol Phys 70 (2008), 13431349.

[41] R.L. Hintz, K.M. Attie, J. Baptista and A. Roche, Effect of growth hormone treatment on adult height of children with idiopathic short stature. Genentech Collaborative Group, $N$ Engl J Med 340 (1999), 502-507.

[42] A. Hokken-Koelega, Y. van Pareren and N. Arends, Effects of growth hormone treatment on cognitive function and head circumference in children born small for gestational age, Horm Res 64(Suppl 3) (2005), 95-99.

[43] Z. Huma, F. Boulad, P. Black, G. Heller and C. Sklar, Growth in children after bone marrow transplantation for acute leukemia, Blood 86 (1995), 819-824.

[44] M.R. Hutchison, M.H. Bassett and P.C. White, Insulin-like growth factor-I and fibroblast growth factor, but not growth hormone, affect growth plate chondrocyte proliferation, Endocrinology 148 (2007), 3122-3130.

[45] E.D. Kakkis, J. Muenzer, G.E. Tiller, L. Waber, J. Belmont, M. Passage, B. Izykowski, J. Phillips, R. Doroshow, I. Walot, R. Hoft and E.F. Neufeld, Enzyme-replacement therapy in mucopolysaccharidosis I, N Engl J Med 344 (2001), 182188.

[46] H. Kanazawa, H. Tanaka, M. Inoue, Y. Yamanaka, N. Namba and Y. Seino, Efficacy of growth hormone therapy for patients with skeletal dysplasia, J Bone Miner Metab 21 (2003), 307310.

[47] N. Kandemir, E.N. Gonc and N. Yordam, Responses of bone turnover markers and bone mineral density to growth hormone therapy in children with isolated growth hormone deficiency and multiple pituitary hormone deficiencies, J Pediatr Endocrinol Metab 15 (2002), 809-816.

[48] L.L. Key, Jr. and A.J. Gross, Response to growth hormone in children with chondrodysplasia, J Pediatr 128 (1996), S14S17.

[49] G. Khanna, A.E. Van Heest, J. Agel, K. Bjoraker, S. Grewal, S. Abel, W. Krivit, C. Peters and P.J. Orchard, Analysis of factors affecting development of carpal tunnel syndrome in patients with Hurler syndrome after hematopoietic cell transplantation, Bone Marrow Transplant 39 (2007), 331334.

[50] W. Krivit, Allogeneic stem cell transplantation for the treatment of lysosomal and peroxisomal metabolic diseases, Springer Semin Immunopathol 26 (2004), 119-132.

[51] R. Lanes, P. Gunczler, S. Esaa and J.R. Weisinger, The effect of short- and long-term growth hormone treatment on bone mineral density and bone metabolism of prepubertal children with idiopathic short stature: a 3-year study, Clin Endocrinol (Oxf) 57 (2002), 725-730.

[52] L. Legault and Y. Bonny, Endocrine complications of bone marrow transplantation in children, Pediatr Transplant 3 (1999), 60-66.

[53] J. Leger, I. Mercat, C. Alberti, D. Chevenne, P. Armoogum, J. Tichet and P. Czernichow, The relationship between the GH/ IGF-I axis and serum markers of bone turnover metabolism in healthy children, Eur J Endocrinol 157 (2007), 685-692.

[54] S.E. Lerner, G.J. Huang, D. McMahon, C.A. Sklar and S.E. Oberfield, Growth hormone therapy in children after cranial/craniospinal radiation therapy: sexually dimorphic outcomes, J Clin Endocrinol Metab 89 (2004), 6100-6104.

[55] E.W. Leschek, S.R. Rose, J.A. Yanovski, J.F. Troendle, C.A. Quigley, J.J. Chipman, B.J. Crowe, J.L. Ross, F.G. Cassorla, W.F. Blum, G.B. Cutler, Jr. and J. Baron, Effect of growth hormone treatment on adult height in peripubertal children with idiopathic short stature: a randomized, double-blind, placebo-controlled trial, J Clin Endocrinol Metab 89 (2004), 3140-3148.

[56] C.E. MacFarlane, D.C. Brown, L.B. Johnston, M.A. Patton, D.B. Dunger, M.O. Savage, W.J. McKenna and C.J. Kelnar, Growth hormone therapy and growth in children with Noonan's syndrome: results of 3 years' follow-up, J Clin Endocrinol Metab 86 (2001), 1953-1956.

[57] M.A. Monroy, F.P. Ross, S.L. Teitelbaum and M.S. Sands, Abnormal osteoclast morphology and bone remodeling in a murine model of a lysosomal storage disease, Bone 30 (2002), 352-359.

[58] A.M. Montano, S. Tomatsu, A. Brusius, M. Smith and T. Orii, Growth charts for patients affected with Morquio A disease, Am J Med Genet A 146A (2008), 1286-1295.

[59] A.M. Montano, S. Tomatsu, G.S. Gottesman, M. Smith and T. Orii, International Morquio A Registry: clinical manifestation and natural course of Morquio A disease, $J$ Inherit Metab Dis 30 (2007), 165-174.

[60] J. Muenzer, J.E. Wraith, M. Beck, R. Giugliani, P. Harmatz, C.M. Eng, A. Vellodi, R. Martin, U. Ramaswami, M. Gucsavas-Calikoglu, S. Vijayaraghavan, S. Wendt, A.C. Puga, B. Ulbrich, M. Shinawi, M. Cleary, D. Piper, A.M. Conway and A. Kimura, A phase II/III clinical study of enzyme replacement therapy with idursulfase in mucopolysaccharidosis II (Hunter syndrome), Genet Med 8 (2006), 465-473.

[61] S.E. Myers, A.L. Carrel, B.Y. Whitman and D.B. Allen, Sustained benefit after 2 years of growth hormone on body composition, fat utilization, physical strength and agility, and growth in Prader-Willi syndrome, J Pediatr 137 (2000), 4249.

[62] S.E. Myers, B.Y. Whitman, A.L. Carrel, V. Moerchen, M.T. Bekx and D.B. Allen, Two years of growth hormone therapy 
in young children with Prader-Willi syndrome: physical and neurodevelopmental benefits, Am J Med Genet A 143 (2007), 443-448.

[63] T. Nagai, K. Obata, T. Obata, N. Murakami, Y. Katada, A. Yoshino, S. Sakazume, Y. Tomita, R. Sakuta and N. Niikawa, Growth Hormone Therapy and Scoliosis in Patients with Prader-Willi Syndrome, American Journal of Medical Genetics Part A 140A (2006), 1623-1627.

[64] K. Nagashima, H. Endo, K. Sakakibara, Y. Konishi, K. Miyachi, J.J. Wey, Y. Suzuki and J. Onisawa, Morphological and biochemical studies of a case of mucopolysaccharidosis II (Hunter's syndrome), Acta Pathol Jpn 26 (1976), 115-132.

[65] E. Neufeld, The Mucopolysaccharidoses, in: The metabolic and molecular basis of inherited disease, C. Scriver, McGraw-Hill, 2001, 3421-3452.

[66] J.D. Nuttall, L.K. Brumfield, N.L. Fazzalari, J.J. Hopwood and S. Byers, Histomorphometric analysis of the tibial growth plate in a feline model of mucopolysaccharidosis type VI, Calcif Tissue Int 65 (1999), 47-52.

[67] H. Oda, Y. Sasaki, Y. Nakatani, H. Maesaka and S. Suwa, Hunter's syndrome. An ultrastructural study of an autopsy case, Acta Pathol Jpn 38 (1988), 1175-1190.

[68] Online Mendelian Inheritance in Man, OMIM, in: Book Online Mendelian Inheritance in Man, OMIM, Editor, McKusick-Nathans Institute for Genetic Medicine, Johns Hopkins University and National Center for Biotechnology Information, National Library of Medicine, 2000,

[69] L.E. Polgreen, J. Tolar, M. Plog, J.H. Himes, P.J. Orchard, C.B. Whitley, B.S. Miller and A. Petryk, Growth and endocrine function in patients with Hurler syndrome after hematopoietic stem cell transplantation, Bone Marrow Transplant 41 (2008), 1005-1011.

[70] L.E. Polgreen, M. Plog, J.D. Schwender, J. Tolar, W. Thomas, P.J. Orchard, B.S. Miller and A. Petryk, Short-term growth hormone treatment in children with Hurler syndrome after hematopoietic cell transplantation, Bone Marrow Transplant 44 (2009), 279-285.

[71] C. Quigley, A. Gill, B. Crowe, K. Robling, J. Chipman, S. Rose, J. Ross, F. Cassorla, A. Wolka, J.M. Wit, L. RekersMombarg and G. Cutler, Safety of Growth Hormone Treatment in Pediatric Patients with Idiopathic Short Stature, $J$ Clin Endocrinol Metab 90 (2005), 5188-5196.

[72] U. Ramaswami, G. Rumsby, H.A. Spoudeas, P.C. Hindmarsh and C.G. Brook, Treatment of achondroplasia with growth hormone: six years of experience, Pediatr Res 46 (1999), 435-439.

[73] M.B. Ranke, C.P. Schwarze, R. Dopfer, T. Klingebiel, H.G. Scheel-Walter, P. Lang and D. Niethammer, Late effects after stem cell transplantation (SCT) in children-growth and hormones, Bone Marrow Transplant 35(Suppl 1) (2005), S77S81.

[74] J.L. Ross, D.E. Sandberg, S.R. Rose, E.W. Leschek, J. Baron, J.J. Chipman, F.G. Cassorla, C.A. Quigley, B.J. Crowe, K. Roberts and G.B. Cutler, Jr., Psychological adaptation in children with idiopathic short stature treated with growth hormone or placebo, J Clin Endocrinol Metab 89 (2004), 4873-4878.

[75] J.L. Ross, Effects of growth hormone on cognitive function, Horm Res 64(Suppl 3) (2005), 89-94.

[76] J.L. Ross, P. Feuillan, H. Kushner, D. Roeltgen and G.B. Cutler, Jr., Absence of growth hormone effects on cognitive function in girls with Turner syndrome, J Clin Endocrinol Metab 82 (1997), 1814-1817.

[77] J. Rovet and J. Holland, Psychological aspects of the Cana- dian randomized controlled trial of human growth hormone and low-dose ethinyl oestradiol in children with Turner syndrome. The Canadian Growth Hormone Advisory Group, Horm Res 39(Suppl 2) (1993), 60-64.

[78] C. Russell, G. Hendson, G. Jevon, T. Matlock, J. Yu, M. Aklujkar, K.Y. Ng and L.A. Clarke, Murine MPS I: insights into the pathogenesis of Hurler syndrome, Clin Genet $\mathbf{5 3}$ (1998), 349-361.

[79] G. Saggese, G.I. Baroncelli, S. Bertelloni and S. Barsanti, The effect of long-term growth hormone $(\mathrm{GH})$ treatment on bone mineral density in children with GH deficiency. Role of $\mathrm{GH}$ in the attainment of peak bone mass, J Clin Endocrinol Metab 81 (1996), 3077-3083.

[80] R. Schweizer, D.D. Martin, E. Schonau and M.B. Ranke, Muscle function improves during growth hormone therapy in short children born small for gestational age: results of a peripheral quantitative computed tomography study on body composition, J Clin Endocrinol Metab 93 (2008), 29782983.

[81] R. Schweizer, D.D. Martin, M. Haase, J. Roth, B. Trebar, G. Binder, C.P. Schwarze and M.B. Ranke, Similar effects of long-term exogenous growth hormone $(\mathrm{GH})$ on bone and muscle parameters: a pQCT study of GH-deficient and smallfor-gestational-age (SGA) children, Bone 41 (2007), 875881.

[82] S. Shalitin, M. Phillip, J. Stein, Y. Goshen, D. Carmi and I. Yaniv, Endocrine dysfunction and parameters of the metabolic syndrome after bone marrow transplantation during childhood and adolescence, Bone Marrow Transplant 37 (2006), 1109-1117.

[83] M. Sifuentes, R. Doroshow, R. Hoft, G. Mason, I. Walot, M. Diament, S. Okazaki, K. Huff, G.F. Cox, S.J. Swiedler and E.D. Kakkis, A follow-up study of MPS I patients treated with laronidase enzyme replacement therapy for 6 years, $\mathrm{Mol}$ Genet Metab 90 (2007), 171-180.

[84] C.P. Silveri, F.S. Kaplan, M.D. Fallon, E. Bayever and C.S. August, Hurler syndrome with special reference to histologic abnormalities of the growth plate, Clin Orthop Relat Res (1991), 305-311.

[85] D. Simon, A.M. Prieur, P. Quartier, J. Charles Ruiz and P. Czernichow, Early recombinant human growth hormone treatment in glucocorticoid-treated children with juvenile idiopathic arthritis: a 3-year randomized study, J Clin Endocrinol Metab 92 (2007), 2567-2573.

[86] B.W. Soper, A.W. Pung, C.A. Vogler, J.H. Grubb, W.S. Sly and J.E. Barker, Enzyme replacement therapy improves reproductive performance in mucopolysaccharidosis type VII mice but does not prevent postnatal losses, Pediatr Res $\mathbf{4 5}$ (1999), 180-186.

[87] S.L. Staba, M.L. Escolar, M. Poe, Y. Kim, P.L. Martin, P. Szabolcs, J. Allison-Thacker, S. Wood, D.A. Wenger, P. Rubinstein, J.J. Hopwood, W. Krivit and J. Kurtzberg, Cord-blood transplants from unrelated donors in patients with Hurler's syndrome, N Engl J Med 350 (2004), 1960-1969.

[88] N. Tanaka, N. Katsumata, R. Horikawa and T. Tanaka, The comparison of the effects of short-term growth hormone treatment in patients with achondroplasia and with hypochondroplasia, Endocr J 50 (2003), 69-75.

[89] J. Tolar, S.S. Grewal, K.J. Bjoraker, C.B. Whitley, E.G. Shapiro, L. Charnas and P.J. Orchard, Combination of enzyme replacement and hematopoietic stem cell transplantation as therapy for Hurler syndrome, Bone Marrow Transplant 41 (2008), 531-535.

[90] S.P. Toledo, V.H. Costa, R.R. Fukui and N. Abelin, [Serum 
growth hormone levels in Hunter's syndrome], Rev Hosp Clin Fac Med Sao Paulo 46 (1991), 9-13.

[91] A. Tylki-Szymanska and M. Metera, Precocious puberty in three boys with Sanfilippo A (mucopolysaccharidosis III A), J Pediatr Endocrinol Metab 8 (1995), 291-293.

[92] L.E. Underwood, K.M. Attie and J. Baptista, Growth hormone $(\mathrm{GH})$ dose-response in young adults with childhoodonset GH deficiency: a two-year, multicenter, multipledose, placebo-controlled study, J Clin Endocrinol Metab $\mathbf{8 8}$ (2003), 5273-5280

[93] A. Vellodi, E. Young, M. New, C. Pot-Mees and K. HughJones, Bone marrow transplantation for Sanfilippo disease type B, J Inherit Metab Dis 15 (1992), 911-918.

[94] A. Vellodi, E.P. Young, A. Cooper, J.E. Wraith, B. Winchester, C. Meaney, U. Ramaswami and A. Will, Bone marrow transplantation for mucopolysaccharidosis type I: experience of two British centres, Arch Dis Child 76 (1997), 92-99.

[95] A. Vidil, P. Journeau, A. Soulie, J. Padovani and J. Pouliquen, Evolution of Scoliosis in Six Children Treated wtih Growth Hormone, J Pediatr Orthopaedics Part B 10 (2001), 197200.

[96] E. Wang, D. Drummond, J. Dormans, T. Moshang, R. Davidson and D. Gruccio, Scoliosis in patients treated with growth hormone, J Pediatr Orthop 17 (1997), 708-711.

[97] J.S. Weisstein, E. Delgado, L.S. Steinbach, K. Hart and S. Packman, Musculoskeletal manifestations of Hurler syndrome: long-term follow-up after bone marrow transplantation, J Pediatr Orthop 24 (2004), 97-101.

[98] C.B. Whitley, The mucopolysaccharidoses, in: McKusick's Heritable Disorders of Connective Tissue, P. Beighton, ed.
Mosby, 1993, pp. 367-500.

[99] W.M. Widdowson and J. Gibney, The effect of growth hormone replacement on exercise capacity in patients with GH deficiency: a metaanalysis, J Clin Endocrinol Metab 93 (2008), 4413-4417.

[100] R.H. Willemsen, N.J. Arends, W.M. Bakker-van Waarde, M. Jansen, E.G. van Mil, J. Mulder, R.J. Odink, M. Reeser, C. Rongen-Westerlaken, W.H. Stokvis-Brantsma, J.J. Waelkens and A.C. Hokken-Koelega, Long-term effects of growth hormone $(\mathrm{GH})$ treatment on body composition and bone mineral density in short children born small-for-gestational-age: six-year follow-up of a randomized controlled GH trial, Clin Endocrinol (Oxf) 67 (2007), 485-492.

[101] J.E. Wraith, M. Scarpa, M. Beck, O.A. Bodamer, L. De Meirleir, N. Guffon, A. Meldgaard Lund, G. Malm, A.T. Van der Ploeg and J. Zeman, Mucopolysaccharidosis type II (Hunter syndrome): a clinical review and recommendations for treatment in the era of enzyme replacement therapy, Eur J Pediatr 167 (2008), 267-277.

[102] G. Zhao, M.C. Monier-Faugere, M.C. Langub, Z. Geng, T. Nakayama, J.W. Pike, S.D. Chernausek, C.J. Rosen, L.R. Donahue, H.H. Malluche, J.A. Fagin and T.L. Clemens, Targeted overexpression of insulin-like growth factor I to osteoblasts of transgenic mice: increased trabecular bone volume without increased osteoblast proliferation, Endocrinology 141 (2000), 2674-2682.

[103] G.D. Zimet, R. Owens, W. Dahms, M. Cutler, M. Litvene and L. Cuttler, Psychosocial outcome of children evaluated for short stature, Arch Pediatr Adolesc Med 151 (1997), 10171023 . 